\title{
Positive thyroid antibodies and risk of thyroid cancer: A systematic review and meta-analysis
}

\author{
YANG XIAO $^{1,2^{*}}$, QUAN ZHOU ${ }^{3 *}$, YONG XU $^{1}$, SONG-LIN YUAN ${ }^{1}$ and QING-AN LIU ${ }^{1}$ \\ ${ }^{1}$ Department of General Surgery, First People's Hospital of Changde City; ${ }^{2}$ Department of General Surgery, \\ Affiliated Changde Hospital, University of South China; ${ }^{3}$ Department of Science and Education, \\ First People's Hospital of Changde City, Changde, Hunan 415003, P.R. China
}

Received January 17, 2019; Accepted June 12, 2019

DOI: $10.3892 / \mathrm{mco} .2019 .1886$

\begin{abstract}
Previous studies assessing the association between thyroid antibodies and the risk of thyroid cancer (TC) have produced inconsistent results. The present study therefore conducted a meta-analysis of the available data. PubMed, Embase and the Cochrane Library were searched for the retrieval of relevant studies and a meta-analysis was conducted to systematically evaluate the association between positive thyroid antibodies and the risk of TC. This search identified 16 articles containing 17 studies on thyroglobulin antibodies ( $\operatorname{Tg} \mathrm{Ab}$ ), which involved a total of 34,488 patients. Positive $\mathrm{Tg} \mathrm{Ab}$ was associated with an increased risk of TC [odds ratio $(\mathrm{OR})=1.93,95 \%$ confidence interval $(\mathrm{CI})=1.64-2.27$, $\left.\mathrm{I}^{2}=67.2 \%\right]$. Whether to adjust for confounding factors (gender and thyroid nodule number) was the main cause of heterogeneity. A stronger association between positive $\operatorname{Tg} \mathrm{Ab}$ and an increased risk of TC was identified in the studies with an unadjusted thyroid nodule number $(\mathrm{OR}=2.14,95 \% \mathrm{CI}=1.82-2.52)$, as compared to those with an adjusted thyroid nodule number $(\mathrm{OR}=1.61,95 \% \mathrm{CI}=1.29-2.00 ; \mathrm{P}=0.04)$. In addition, 12 studies on thyroid peroxidase antibodies (TPOAb) involving 30,007 patients were included. Positive TPOAb was associated with an increased risk of TC $(\mathrm{OR}=1.50,95 \% \mathrm{CI}=1.16-1.95$, $\left.\mathrm{I}^{2}=83.0 \%\right)$. No significant heterogeneity was observed in the PTC group. Positive TgAb is an independent risk factor for TC. The association between positive TPOAb and increased risk of TC needs to be further studied.
\end{abstract}

Correspondence to: Mr. Qing-An Liu or Mr. Song-Lin Yuan, Department of General Surgery, First People's Hospital of Changde City, 818 Renmin Road, Changde, Hunan 415003, P.R. China

E-mail: 13975616413@163.com

E-mail: 476926917@qq.com

*Contributed equally

Key words: thyroid cancer, thyroglobulin antibodies, thyroid peroxidase antibodies, meta-analysis

\section{Introduction}

Thyroid nodules are a common disease of the neck, with malignant nodules accountings for $5-15 \%$ of them (1). The pathological classification of thyroid cancer (TC) includes papillary, follicular and undifferentiated types. Except from painless nodules, TC usually has no other specific clinical symptom, making it harder to detect at an early stage. In recent years, the incidence of TC has gradually increased, ranking 9th among all tumors worldwide (2-5). Early diagnosis of TC and surgical treatment are particularly important for the prognosis of patients.

The most accurate examination for preoperative diagnosis of TC, thyroid fine needle aspiration cytology (FNAC) is unable to distinguish between thyroid follicular carcinoma and follicular adenoma. Recent studies found that measuring $\mathrm{Tg} \mathrm{Ab}$ could help differentiate $\mathrm{TC}$ from indeterminate nodules subjected to FNAC (6-8).

$\mathrm{Tg} \mathrm{Ab}$, an IgG glycoprotein secreted by lymphoid B cells, and thyroid peroxidase antibodies (TPOAb) usually indicates autoimmune thyroid diseases (AITD) when they are positive. These two antibodies could also be elevated in patients with TC (9). Recently, more and more studies have focused on the relationship between thyroid antibodies and TC. An early study found that the prevalence rate of positive $\operatorname{TgAb}$ in patients with TC was 2.5 times as much as in the general population (9). Kim et al (10) first reported that $\mathrm{TgAb}$ could be used as an independent predictor for TC diagnosis ( $\mathrm{OR}=1.80,95 \%$ $\mathrm{CI}=1.29-2.58$ ), regardless of the presence of AITD, especially in younger patients (11). Furthermore, TC patients with positive $\operatorname{TgAb}$ levels had a worse prognosis after surgery $(12,13)$. However, this issue remains controversial. The present meta-analysis was therefore performed to systematically evaluate the association between positive thyroid antibodies $(\mathrm{Tg} \mathrm{Ab}$ and $\mathrm{TPOAb})$ and the risk of TC.

\section{Materials and methods}

Search strategy. A systematic search was conducted using three electronic databases (Pubmed, Embase and Cochrane library) to retrieve potentially relevant articles published before October 2018. The search strategy comprised the terms (all fields) 'thyroid cancer', 'thyroid carcinoma', 'thyroid 


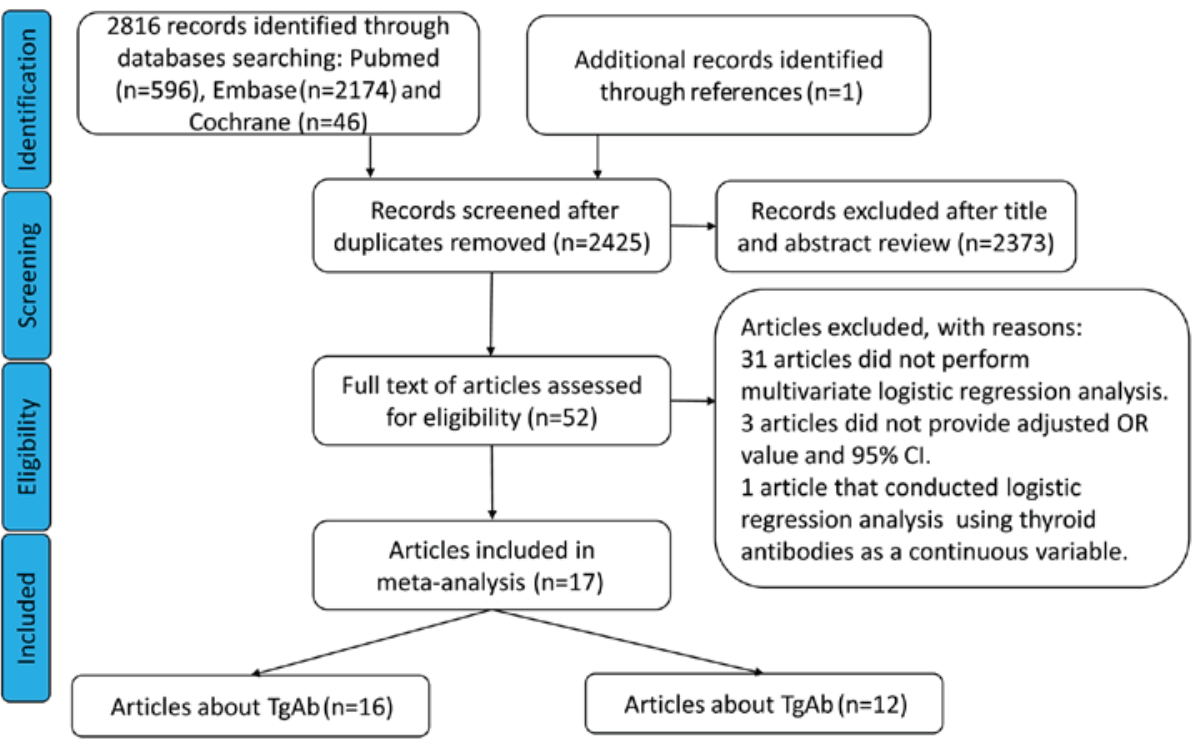

Figure 1. Study selection flowchart for the meta-analysis.

neoplasm', or 'thyroid nodule', and 'thyroglobulin antibody', 'thyroglobulin autoantibody', 'thyroid peroxidase antibody', 'thyroid peroxidase autoantibody', 'thyroid antibody', 'thyroid autoantibody', 'TgAb' or 'TPOAb'. We also searched for relevant articles from references of the original paper and review articles.

Selection criteria. The inclusion criteria were as follows: i) Studies explored the association between preoperative serum thyroid antibodies (TgAb or TPOAb), as a categorical variable, and the risk of $\mathrm{TC}$; ii) patients with $\mathrm{TC}$ and thyroid benign nodules were classified into case group and control group, respectively; iii) the diagnosis of $\mathrm{TC}$ was based on preoperative FNAC or postoperative histological biopsy. Reviews, duplicate literatures, the meeting abstract and the studies that did not provide odds ratio (OR) and the corresponding $95 \%$ confidence intervals (CI) data adjusted by multivariate logistic regression analysis were excluded.

Data extraction. Two researchers independently extracted important information from the selected literature. The extracted data included: The first author, year of publication, study location, sample size, cancer types, confounding factors, OR values and 95\% CI adjusted by multivariate logistic regression analysis.

Quality evaluation. The Newcastle-Ottawa Scale (14) was used to evaluate the quality of the selected literature. This scale is three dimensional: Selection, comparability and exposure, with a score range of 0-9. Scores of 0-6 were classified as low-quality studies and scores of 7-9 as high-quality studies.

Statistical analysis. Statistical analysis was carried out using STATA 14.0 software. The heterogeneity across studies was estimated using the I-squared statistic and Cochran's Q-test. If there was significant heterogeneity $\left(\mathrm{I}^{2}>50 \%\right.$ or $\left.\mathrm{P}<0.10\right)$, the random effects model was used for meta-analysis. Next, a Galbraith plot was used to investigate the source of heterogeneity from single studies. At the same time, meta-regression and subgroup analyses were performed based on the characteristics of studies to identify factors that contributed to heterogeneity. Otherwise, the fixed effects model was used. The pooled OR and 95\%CI were calculated to evaluate the association between positive thyroid antibodies and the risk of TC. Z test was used to determine the significance of this association. Sensitivity analysis was performed to explore the influence of a single study on the overall risk estimate by omitting one study in each turn. Begg rank correlation test and Egger's regression test were used to estimate the publication bias, and the result of meta-analysis was corrected using the trim-and-fill method, if publication bias was identified. $\mathrm{P}<0.05$ was considered to indicate a statistically significant difference.

\section{Results}

Literature search and study characteristics. Our search identified 2,817 potentially relevant articles, out of which 392 were duplicates and were deleted (Fig. 1). After reading the title and abstract, 2,373 articles were deleted based on the exclusion criteria. Next, the full text of the remaining 52 articles was reviewed and 35 more were excluded. Finally, 17 articles were included in the meta-analysis $(7,8,10,11,15-27)$. The characteristics of those articles are listed in Table I.

Meta-analysis. Sixteen articles containing 17 studies on the association between $\mathrm{Tg} \mathrm{Ab}$ and the risk of $\mathrm{TC}$ involving 34,488 patients were included, and the pooled OR was 1.93 (95\% CI=1.64-2.27, $\left.\mathrm{I}^{2}=67.2 \%\right)$, based on the random-effects model (Fig. 2). Twelve studies on the association between TPOAb and the risk of TC involving 30,007 patients were included, and the pooled OR was 1.48 (95\% CI=1.15-1.91, $\mathrm{I}^{2}=83.0 \%$ ), based on the random-effects model (Fig. 3).

Heterogeneity analysis. As mentioned above, there was significant heterogeneity across the included studies. In studies about $\mathrm{Tg} \mathrm{Ab}$, the Galbraith radial plot showed that two studies 


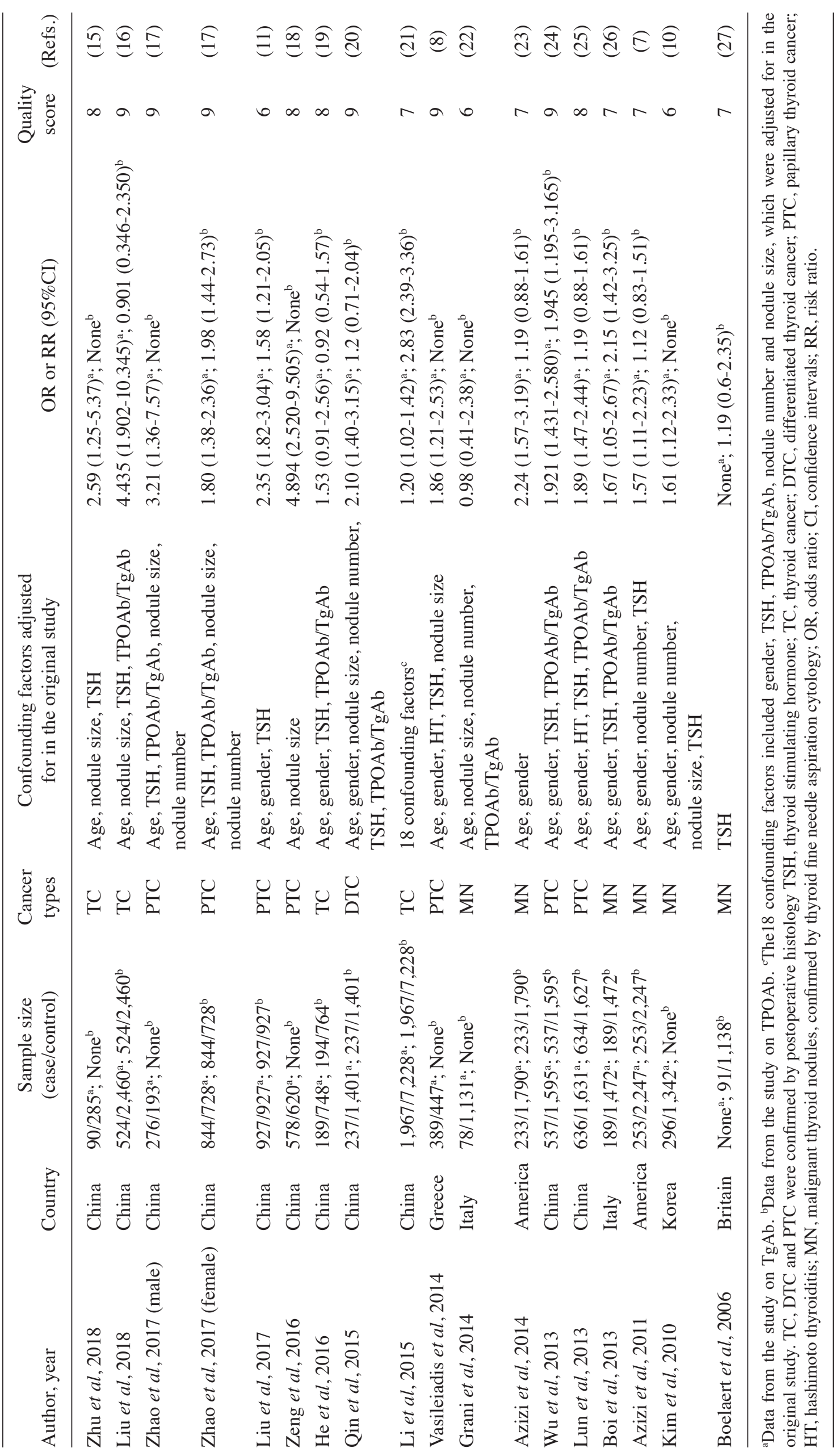




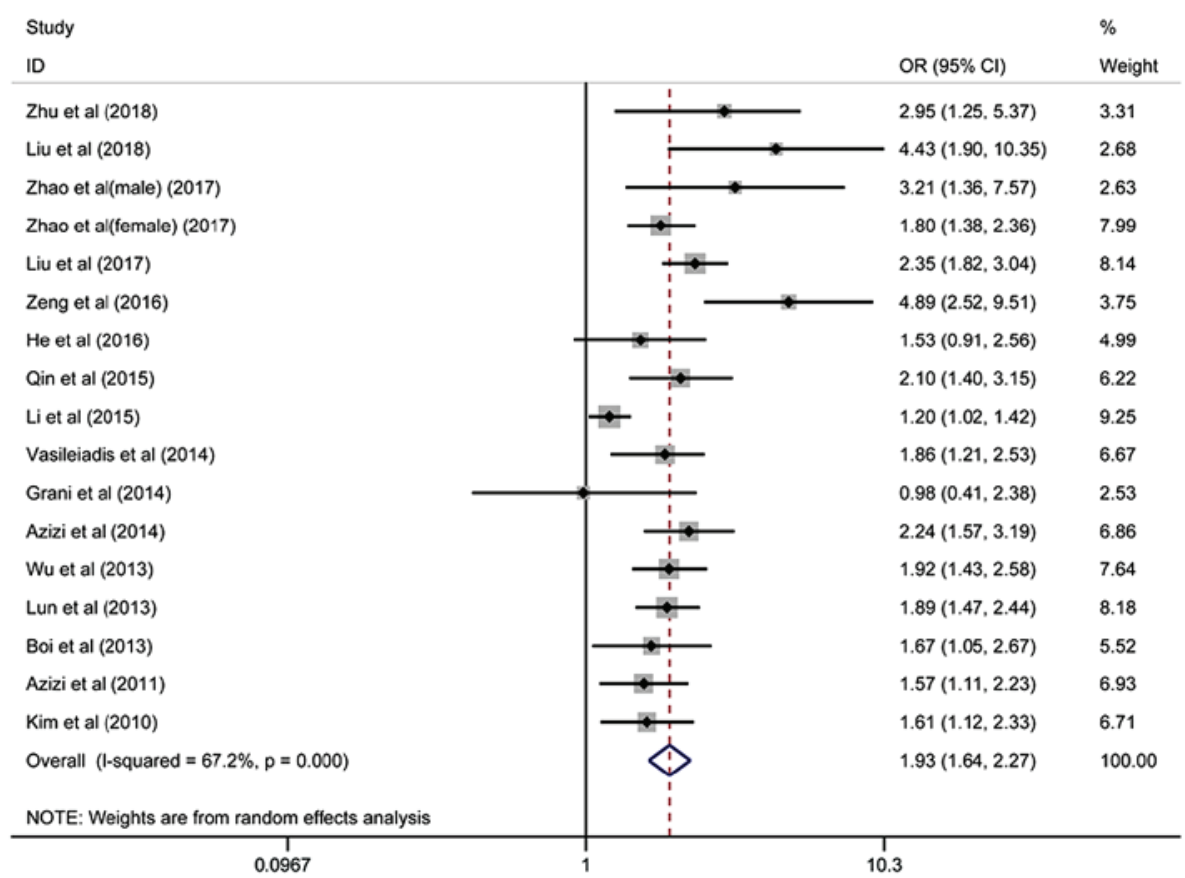

Figure 2. Forest plots for the association between $\operatorname{Tg} \mathrm{Ab}$ and the risk of $\mathrm{TC}$. $\mathrm{Tg} \mathrm{Ab}$, thyroglobulin antibodies; $\mathrm{TC}$, thyroid cancer.

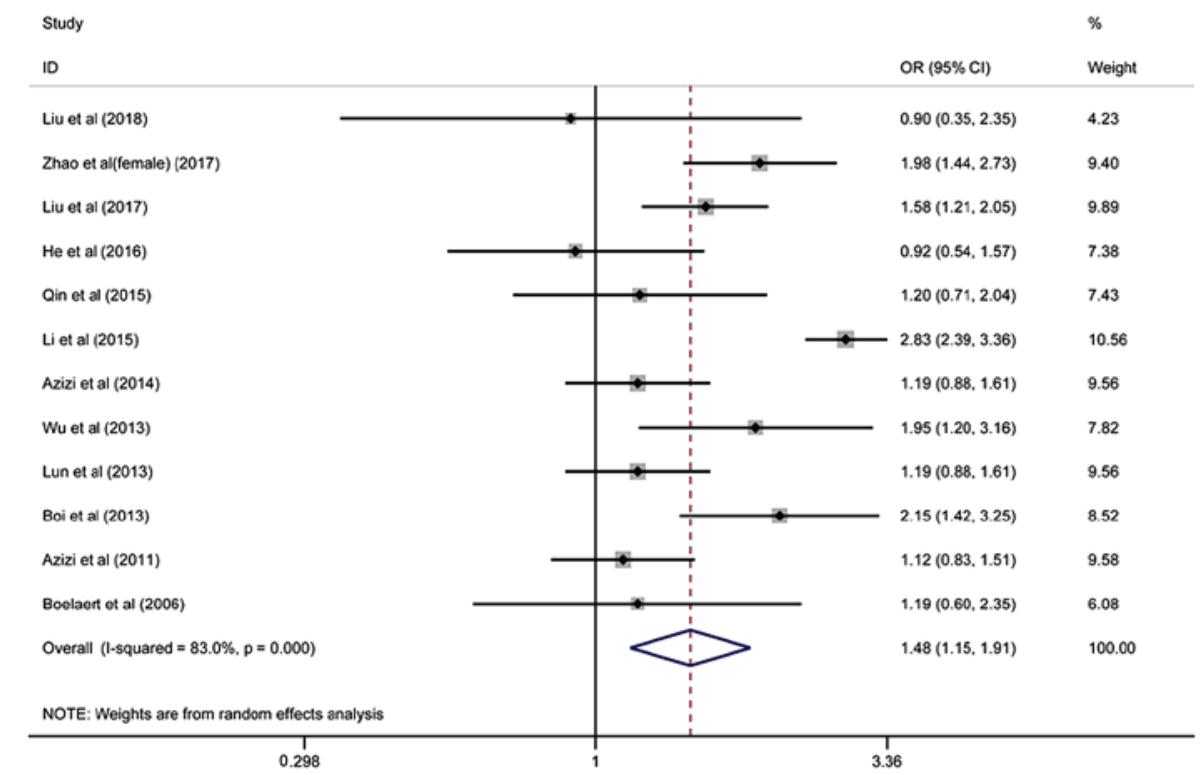

Figure 3. Forest plots for the association between TPOAb and the risk of TC. TPOAb thyroid peroxidase antibodies; TC, thyroid cancer.

caused the heterogeneity $(18,21)$ (Fig. 4). After removing the two studies, we found that the rest of the included studies were homogeneous $\left(\mathrm{I}^{2}=9.7 \%, \mathrm{P}=0.35\right)$ and the association between positive $\mathrm{TgAb}$ and the increased risk TC did not change $(\mathrm{OR}=1.93,95 \% \mathrm{CI}=1.74-2.14)$. In addition, meta-regression analysis was conducted based on the characteristics of studies including study location, cancer types, sample size and confounding factors. The results indicated that confounding factors (gender and thyroid nodule number) were responsible for $74.6 \%$ of the heterogeneity $(\mathrm{P}<0.05)$.

In studies on TPOAb, Li et al (21) and Zhao et al (17) (female) study data were the causes of heterogeneity (Fig. 5). The association between positive TPOAb and increased risk of TC did not change $(\mathrm{OR}=1.33,95 \% \mathrm{CI}=1.13-1.57)$ and the heterogeneity became not significant $\left(\mathrm{I}^{2}=36.5 \%, \mathrm{P}=0.12\right)$ following the removal of the two studies. Meta-regression analysis did not identify the characteristics of studies that led to heterogeneity. It only showed non-significant heterogeneity in the PTC group.

Subgroup analysis. In studies on $\mathrm{Tg} \mathrm{Ab}$, positive $\mathrm{Tg} \mathrm{Ab}$ was associated with an increased risk of TC in all subgroups. A stronger association was found in studies that did not adjust the thyroid nodule number $(\mathrm{OR}=2.14,95 \% \mathrm{CI}=1.82-2.52)$, as compared with studies that did $(\mathrm{OR}=1.61,95 \% \mathrm{CI}=1.29-2.00$; $\mathrm{P}=0.04)$. 


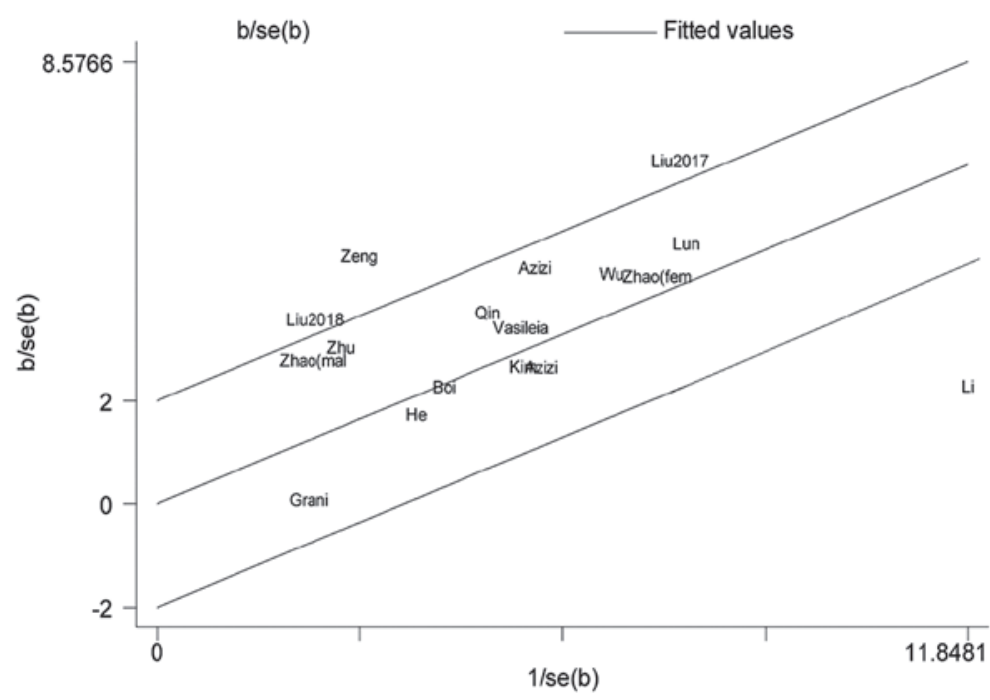

Figure 4. Galbraith radial plot for the heterogeneity across studies on $\operatorname{Tg} \mathrm{Ab}$. $\operatorname{Tg} \mathrm{Ab}$, thyroglobulin antibodies.

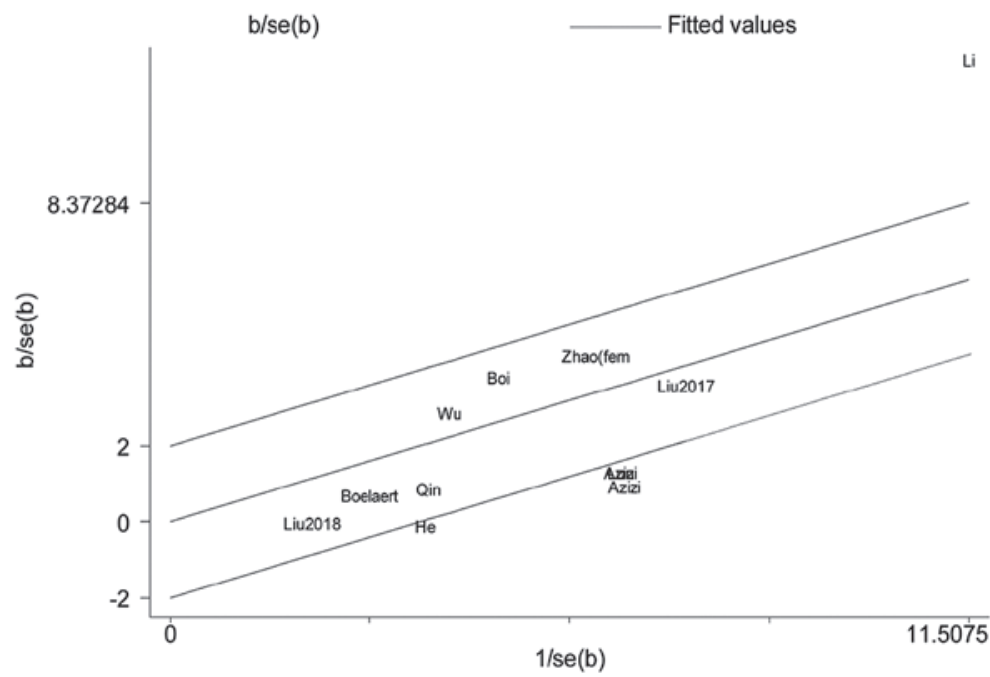

Figure 5. Galbraith radial plot for the heterogeneity across studies on TPOAb. TPOAb, thyroid peroxidase antibodies.

In studies on TPOAb, no association between TPOAb and the risk of TC was observed in the TC group and big sample size group (Table II).

Sensitivity analysis. Sensitivity analysis found that the removal of any studies on $\mathrm{TgAb}$ or TPOAb did not affect the pooled OR values and $95 \% \mathrm{CI}$, suggesting that the results of our meta-analysis were stable and not influenced by a single study.

Publication bias. In studies on $\operatorname{Tg} \mathrm{Ab}$, the funnel plot was asymmetrical, indicating the presence of potential publication bias ( $\mathrm{P}=0.02$; Fig. 6 ), whereas publication bias did not exist $(\mathrm{P}=0.28)$ following the removal of the data from the study by Li et al (21), which was the biggest sample size study and source of heterogeneity. This suggested that the essential difference between smaller and larger studies that arises from heterogeneity across studies was the cause of the asymmetry of the funnel plot (28). Despite that, the trim-and-fill method was used right away and the corrected OR value was found to be 1.61 (95\% CI=1.36-1.91), which was not significantly different from the original OR values, proving the authenticity of the meta-analysis. In studies on TPOAb, both the funnel plot and the Egger test indicated the presence of publication bias $(\mathrm{P}<0.01)$, but no publication bias was observed $(\mathrm{P}=0.11)$ following the removal of the data from the study by Li et al (21) (Fig. 7).

\section{Discussion}

The identification of benign and malignant thyroid nodules has always been in the center of clinical attention. It is controversial whether thyroid antibodies are a risk factor for TC $(22,29-31)$. In the present meta-analysis, $\operatorname{Tg} \mathrm{Ab}$-positive patients were found twice as likely to develop TC as TgAb-negative patients, suggesting that positive $\mathrm{TgAb}$ is a risk factor for TC. Though positive TPOAb is associated with an increased risk of TC, this association did not exist in some subgroups, which may have been due to the small sample size of those subgroups. 
Table II. Subgroup analysis to probe differences in the pooled OR values between studies included in the meta-analysis.

$\mathrm{A}, \operatorname{TgAb}$

\begin{tabular}{|c|c|c|c|c|}
\hline \multirow[b]{2}{*}{ Variables } & \multirow[b]{2}{*}{ Pooled OR (95\%CI) } & \multicolumn{2}{|c|}{ Test of heterogeneity } & \multirow[b]{2}{*}{ P-value } \\
\hline & & $\mathrm{I}^{2}(\%)$ & P-value & \\
\hline Study location & & & & 0.34 \\
\hline Occident $(n=5)$ & $1.78(1.48-2.14)$ & 0.2 & 0.405 & \\
\hline Asia $(n=12)$ & $2.05(1.66-2.53)$ & 75.4 & 0 & \\
\hline Cancer type & & & & 0.29 \\
\hline $\mathrm{TC}(\mathrm{n}=4)$ & $1.99(1.14-3.46)$ & 78.8 & 0.003 & \\
\hline DTC $(n=1)$ & $2.10(0.89-2.65)$ & - & - & \\
\hline PTC $(n=7)$ & $2.11(1.77-2.50)$ & 42.8 & 0.105 & \\
\hline $\mathrm{MN}(=5)$ & $1.72(1.42-2.07)$ & 2.6 & 0.392 & \\
\hline Sample size & & & & 0.16 \\
\hline$>1,200(=12)$ & $1.81(1.52-2.15)$ & 68.3 & 0 & \\
\hline$<1,200(=5)$ & $2.48(1.65-3.75)$ & 58.4 & 0.048 & \\
\hline Adjusted for nodule number & & & & 0.04 \\
\hline Yes $(n=7)$ & $1.61(1.29-2.00)$ & 60.8 & 0.018 & \\
\hline No $(n=10)$ & $2.14(1.82-2.52)$ & 38.9 & 0.099 & \\
\hline Adjusted for nodule size & & & & 0.76 \\
\hline Yes $(n=10)$ & $2.04(1.54-2.70)$ & 76.1 & 0 & \\
\hline No $(n=7)$ & $1.95(1.72-2.20)$ & 0 & 0.489 & \\
\hline Adjusted for gender & & & & 0.18 \\
\hline Yes $(n=13)$ & $1.80(1.56-2.09)$ & 61.00 & 0.002 & \\
\hline No $(n=4)$ & $2.90(1.48-5.69)$ & 67.10 & 0.028 & \\
\hline
\end{tabular}

$\mathrm{B}, \mathrm{TPOAb}$

Test of heterogeneity

\begin{tabular}{|c|c|c|c|c|}
\hline \multirow[b]{2}{*}{ Variables } & \multirow[b]{2}{*}{ Pooled OR (95\%CI) } & & \multirow[b]{2}{*}{ P-value } \\
\hline & & $\mathrm{I}^{2}(\%)$ & P-value & \\
\hline Study location & & & & 0.53 \\
\hline Occident $(n=4)$ & $1.35(1.00-1.82)$ & 57.3 & 0.071 & \\
\hline Asia $(n=8)$ & $1.55(1.13-2.12)$ & 84.2 & 0 & \\
\hline Cancer type & & & & 0.66 \\
\hline $\mathrm{TC}(\mathrm{n}=3)$ & $1.41(0.56-3.51)$ & 89.9 & 0 & \\
\hline DTC $(n=1)$ & $1.20(0.71-2.03)$ & - & - & \\
\hline PTC $(n=4)$ & $1.60(1.27-2.02)$ & 50 & 0.112 & \\
\hline $\mathrm{MN}(=4)$ & $1.35(1.00-1.82)$ & 57.3 & 0.071 & \\
\hline Sample size & & & & 0.85 \\
\hline$>2,000(=6)$ & $1.46(0.95-2.26)$ & 90.6 & 0 & \\
\hline$<2,000(=6)$ & $1.54(1.21-1.95)$ & 48.3 & 0.085 & \\
\hline Adjusted for nodule number & & & & 0.46 \\
\hline Yes $(n=4)$ & $1.69(1.03-2.78)$ & 91 & 0 & \\
\hline No $(n=8)$ & $1.39(1.14-1.69)$ & 43.2 & 0.091 & \\
\hline Adjusted for nodule size & & & & 0.27 \\
\hline Yes $(n=4)$ & $1.79(1.14-2.79)$ & 80 & 0.001 & \\
\hline No $(n=8)$ & $1.36(1.13-1.63)$ & 47.5 & 0.064 & \\
\hline
\end{tabular}

P-values were used to assess the subgroup differences. TC, DTC and PTC were confirmed by postoperative histology. TC, thyroid cancer; DTC, differentiated thyroid cancer; PTC, papillary thyroid cancer; MN, malignant thyroid nodules (confirmed by thyroid fine needle aspiration cytology). 


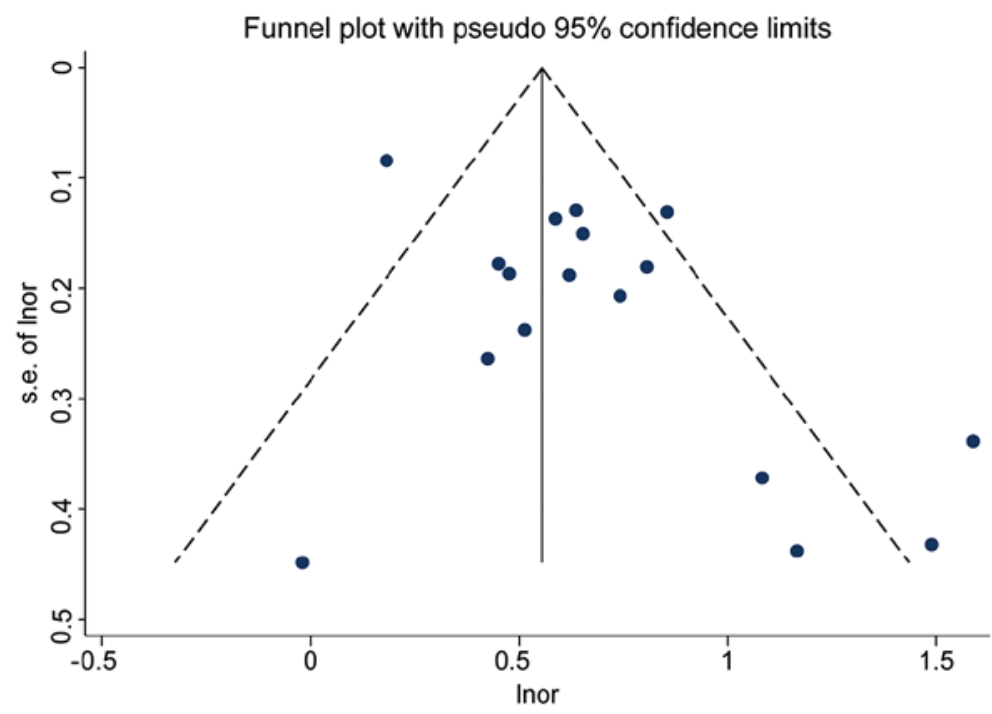

Figure 6. Funnel plot for publication bias test in the meta-analysis on $\operatorname{Tg} A b$. $\operatorname{Tg} A b$, thyroglobulin antibodies.

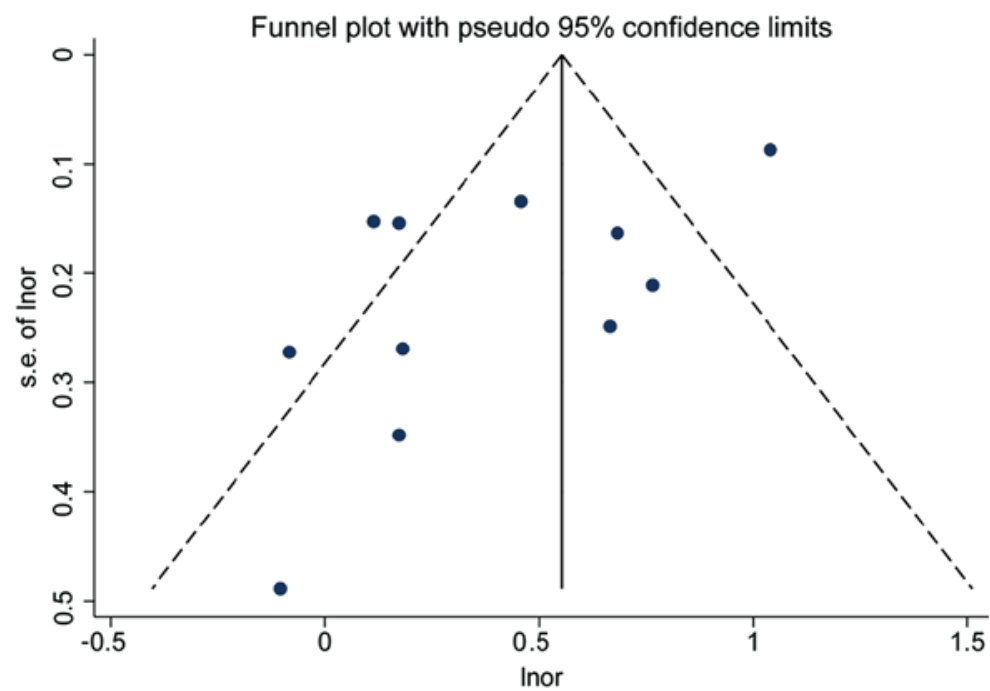

Figure 7. Funnel plot for publication bias test in the meta-analysis on TPOAb. TPOAb thyroid peroxidase antibodies.

Furthermore, the result of the meta-analysis was consistent with a diagnostic study conducted by Hosseini et al (29), which found that the sensitivity and specificity of $\mathrm{Tg} \mathrm{Ab}$ for the diagnosis of TC was $16.04 \%$ (95\% CI=11.37-21.68) and $90.67 \%$ (95\% CI=85.66-94.38), respectively. Therefore, positive $\mathrm{Tg} \mathrm{Ab}$ is specific for $\mathrm{TC}$, although negative $\mathrm{Tg} \mathrm{Ab}$ has little value in eliminating the diagnosis of TC. Certain studies reported that the lower sensitivity of $\mathrm{TgAb}$ may arise from the limitations of assay methods, since using different $\mathrm{Tg} \mathrm{Ab}$ assays could discover discrepancies in the $\mathrm{Tg} \mathrm{Ab}$ status (32-34).

It is well-known that $\mathrm{TgAb}$, combined with TPOAb, used to be a hallmark of AITD. Several studies have discovered an obvious association between AITD with TC, and reported that the coexistence with AITD may be one cause of the elevated serum thyroid antibodies in patients with TC (35-37). However, positive $\mathrm{Tg} A b$ remained a risk factor for TC in studies which excluded AITD patients $(24,25)$. A study showed that the exposure of thyroglobulin antigen during tumor formation could cause an increase in serum $\mathrm{Tg} \mathrm{Ab}$ through immune responses (38). Other studies found that thyroglobulin had $\sim 40$ antigenic sites, which were different between TC and AITD patients $(39,40)$. TC patients exhibited clearly higher core fucose content and an increasing trend of $\mathrm{TgAb}$ sialylation (41). Further research could improve the predictive value of $\mathrm{TgAb}$ for $\mathrm{TC}$ by detecting $\mathrm{TC}$-specific $\mathrm{TgAb}$ fragments.

The present meta-analysis had several following advantages: First, all included studies had performed a multivariate logistic regression analysis that controlled the effects of confounding factors, which fully demonstrated the independent predictive value of $\mathrm{Tg} \mathrm{Ab}$ for TC. Secondly, our analysis included a large sample data from a total of 34,488 thyroid nodules patients in 17 studies on $\mathrm{TgAb}$. Although a moderate to high heterogeneity was observed among those studies $\left(I^{2}=67.2 \%\right)$, the pooled OR value did not change following the removal of the two studies that caused the heterogeneity. It was also found that the differences in confounding factors (thyroid nodule 
number and gender) controlled by the study caused $74.6 \%$ of the heterogeneity. This may be due to differences in cancer rates among people with different genders or thyroid nodule numbers. Nevertheless, the results of both the sensitivity analysis and the trim-and-fill method supported the accuracy of our meta-analysis on the association between positive $\operatorname{Tg} \mathrm{Ab}$ and the increased risk of TC.

However, the present meta-analysis also had certain limitations. First, most of the included studies were retrospective case-control studies and cross-sectional studies, which were unable to articulate the causal relationship between $\mathrm{TgAb}$ and TC. As a result, a multi-center and prospective cohort study is required to further investigate this issue. Secondly, publications bias was identified in our meta-analysis on $\mathrm{Tg} \mathrm{Ab}$. Even though the heterogeneity across studies, particularly that by Li et al (21) that had too big a sample size and was the main source of heterogeneity, led to this bias (28), the result of the trim-and-fill method supported the authenticity of our meta-analysis. Finally, in studies on TPOAb, even though we discovered that the high heterogeneity was derived from single studies $\left(\mathrm{I}^{2}=83.0 \%\right)$, we failed to identify the characteristics of these studies that led to heterogeneity. We therefore did not conduct a meta-analysis on the association between TPOAb and the risk of TC.

In conclusion, positive $\mathrm{Tg} \mathrm{Ab}$ is an independent risk factor for TC. The association between positive TPOAb and the risk of $\mathrm{TC}$ remains to be elucidated.

\section{Acknowledgements}

Not applicable.

\section{Funding}

The Graduate Science Foundation Project of University of South China supported the present study (grant no. 2018KYY497).

\section{Availability of data and materials}

The datasets used and analyzed during the present study are available from the corresponding author on reasonable request.

\section{Authors' contributions}

YaX, QZ, QAL and SLY conceived and designed the experiments. YaX, QZ, QAL, SLY and YoX performed the experiments. YaX and QZ analyzed the data. YaX, QAL, SLY, QZ and YoX wrote the paper.

\section{Ethics approval and consent to participate}

Not applicable.

\section{Patient consent for publication}

Not applicable.

\section{Competing interests}

The authors declare that they have no competing interests.

\section{References}

1. Frates MC, Benson CB, Doubilet PM, Kunreuther E, Contreras M, Cibas ES, Orcutt J, Moore FD Jr, Larsen PR, Marqusee E and Alexander EK: Prevalence and distribution of carcinoma in patients with solitary and multiple thyroid nodules on sonography. J Clin Endocrinol Metab 91: 3411-3417, 2006.

2. Bray F, Ferlay J, Soerjomataram I, Siegel RL, Torre LA and Jemal A: Global cancer statistics 2018: GLOBOCAN estimates of incidence and mortality worldwide for 36 cancers in 185 countries. CA Cancer J Clin 68: 394-424, 2018.

3. Morris LG, Tuttle RM and Davies L: Changing trends in the incidence of thyroid cancer in the united states. JAMA Otolaryngol Head Neck Surg 142: 709-711, 2016.

4. La Vecchia C, Malvezzi M, Bosetti C, Garavello W, Bertuccio P, Levi F and Negri E: Thyroid cancer mortality and incidence: A global overview. Int J Cancer 136: 2187-2195, 2015.

5. Du L, Wang Y, Sun X, Li H, Geng X, Ge M and Zhu Y: Thyroid cancer: Trends in incidence, mortality and clinical-pathological patterns in Zhejiang Province, Southeast China. BMC Cancer 18: 291, 2018.

6. Karatzas T, Vasileiadis I, Zapanti E, Charitoudis G, Karakostas E and Boutzios G: Thyroglobulin antibodies as a potential predictive marker of papillary thyroid carcinoma in patients with indeterminate cytology. Am J Surg 212: 946-952, 2016.

7. Azizi G and Malchoff CD: Autoimmune thyroid disease: A risk factor for thyroid cancer. Endocr Pract 17: 201-209, 2011.

8. Vasileiadis I, Boutzios G, Charitoudis G, Koukoulioti E and Karatzas T: Thyroglobulin antibodies could be a potential predictive marker for papillary thyroid carcinoma. Ann Surg Oncol 21: 2725-2732, 2014

9. Spencer CA, Takeuchi M, Kazarosyan M, Wang CC, Guttler RB, Singer PA, Fatemi S, LoPresti JS and Nicoloff JT: Serum thyroglobulin autoantibodies: Prevalence, influence on serum thyroglobulin measurement, and prognostic significance in patients with differentiated thyroid carcinoma. J Clin Endocrinol Metab 83: 1121-1127, 1998.

10. Kim ES, Lim DJ, Baek KH, Lee JM, Kim MK, Kwon HS, Song KH, Kang MI, Cha BY, Lee KW and Son HY: Thyroglobulin antibody is associated with increased cancer risk in thyroid nodules. Thyroid 20: 885-891, 2010.

11. Liu Y, Li C, Zhao W and Wang Y: Hashimoto's thyroiditis is an important risk factor of papillary thyroid microcarcinoma in younger adults. Horm Metab Res 49: 732-738, 2017.

12. Ernaga-Lorea A, Hernandez-Morhain MC, Anda-Apinaniz E, Pineda-Arribas JJ, Migueliz-Bermejo I, Eguílaz-Esparza N and Irigaray-Echarri A: Prognostic value of change in anti-thyroglobulin antibodies after thyroidectomy in patients with papillary thyroid carcinoma. Clin Transl Oncol 20: 740-744, 2018.

13. Trimboli P, Zilioli V, Imperiali $\mathrm{M}$ and Giovanella L: Thyroglobulin autoantibodies before radioiodine ablation predict differentiated thyroid cancer outcome. Clin Chem Lab Med 55: 1995-2001, 2017.

14. Wells GA, Shea B, O'Connell D, Peterson J, Welch V, Losos M and Tugwell P: The Newcastle-Ottawa Scale (NOS) for assessing the quality of nonrandomised studies in meta-analyses, 2009. Available from: URL: http://www.ohri.ca/programs/ clinical_ epidemiology/ oxford.htm.

15. Zhu C, Li S, Gao X, Zhu G, Song M and Gao F: Retrospective analysis of thyroid nodules: Thyroid cancer risk factors in suzhou, china. Clin Lab 64: 333-338, 2018.

16. Liu J, Zheng D, Li Q, Tang X, Luo Z, Yuan Z, Gao Land Zhao J: A predictive model of thyroid malignancy using clinical, biochemical and sonographic parameters for patients in a multi-center setting. BMC Endocr Disord 18: 17-23, 2018.

17. Zhao H, Li H and Huang T: High urinary iodine, thyroid autoantibodies, and thyroid-stimulating hormone for papillary thyroid cancer risk. Biol Trace Elem Res 184: 317-324, 2017.

18. Zeng R, Shou T, Yang KX, Shen T, Zhang JP, Zuo RX, Zheng YQ and Yan XM: Papillary thyroid carcinoma risk factors in the yunnan plateau of southwestern China. Ther Clin Risk Manag 12: 1065-1074, 2016.

19. He LZ, Zeng TS, Pu L, Pan SX, Xia WF and Chen LL: Thyroid hormones, autoantibodies, ultrasonography, and clinical parameters for predicting thyroid cancer. Int J Endocrinol 2016: 8215834, 2016.

20. Qin J, Yu Z, Guan H, Shi L, Liu Y, Zhao N, Shan Z, Han C, Li Y and Teng W: High thyroglobulin antibody levels increase the risk of differentiated thyroid carcinoma. Dis Markers 2015: 648670, 2015. 
21. Li T, Sheng J, Li W, Zhang X, Yu H, Chen X, Zhang J, Cai Q, Shi Y and Liu Z: A new computational model for human thyroid cancer enhances the preoperative diagnostic efficacy. Oncotarget 6: 28463-28477, 2015.

22. Grani G, Calvanese A, Carbotta G, D'Alessandri M, Nesca A, Bianchini M, Del Sordo M, Vitale M and Fumarola A: Thyroid autoimmunity and risk of malignancy in thyroid nodules submitted to fine-needle aspiration cytology. Head Neck 37: 260-264, 2014

23. Azizi G, Keller JM, Lewis M, Piper K, Puett D, Rivenbark KM and Malchoff CD: Association of hashimoto's thyroiditis with thyroid cancer. Endocr Relat Cancer 21: 845-852, 2014.

24. Wu X, Lun Y, Jiang H, Gang Q, Xin S, Duan Z and Zhang J: Coexistence of thyroglobulin antibodies and thyroid peroxidase antibodies correlates with elevated thyroid-stimulating hormone level and advanced tumor stage of papillary thyroid cancer. Endocrine 46: 554-560, 2013.

25. Lun Y, Wu X, Xia Q, Han Y, Zhang X, Liu Z, Wang F, Duan Z, Xin $\mathrm{S}$ and Zhang J: Hashimoto's thyroiditis as a risk factor of papillary thyroid cancer may improve cancer prognosis. Otolaryngol Head Neck Surg 148: 396-402, 2013.

26. Boi F, Minerba L, Lai ML, Marziani B, Figus B, Spanu F, Borghero A and Mariotti S: Both thyroid autoimmunity and increased serum TSH are independent risk factors for malignancy in patients with thyroid nodules. J Endocrinol Invest 36 : 313-320, 2013.

27. Boelaert K, Horacek J, Holder RL, Watkinson JC, Sheppard MC and Franklyn JA: Serum thyrotropin concentration as a novel predictor of malignancy in thyroid nodules investigated by fine-needle aspiration. J Clin Endocrinol Metab 91: 4295-4301, 2006.

28. Lau J, Ioannidis JP, Terrin N, Schmid CH and Olkin I: The case of the misleading funnel plot. BMJ 333: 597-600, 2006.

29. Hosseini S, Payne RJ, Zawawi F, Mlynarek A, Hier MP, Tamilia M and Forest VI: Can preoperative thyroglobulin antibody levels be used as a marker for well differentiated thyroid cancer? J Otolaryngol Head Neck Surg 45: 31, 2016.

30. Gabalec F, Srbova L, Nova M, Hovorkova E, Hornychova H, Jakubikova I, Ryska A and Cap J: Impact of hashimoto's thyroiditis, TSH levels, and anti-thyroid antibody positivity on differentiated thyroid carcinoma incidence. Endokrynol Pol 67: 48-53, 2016.

31. Selek A, Cetinarslan B, Tarkun I, Canturk Z, Ustuner B and Akyay Z: Thyroid autoimmunity: Is really associated with papillary thyroid carcinoma? Eur Arch Otorhinolaryngol 274: 1677-1681, 2017.

32. Donegan D, McIver B and Algeciras-Schimnich A: Clinical consequences of a change in anti-thyroglobulin antibody assays during the follow-up of patients with differentiated thyroid cancer. Endocr Pract 20: 1032-1036, 2014.
33. D'Aurizio F, Metus P, Ferrari A, Caruso B, Castello R, Villalta D, Steffan A, Gaspardo K, Pesente F, Bizzaro N, et al: Definition of the upper reference limit for thyroglobulin antibodies according to the national academy of clinical biochemistry guidelines: Comparison of eleven different automated methods. Auto Immun Highlights 8: 8, 2017.

34. Pickett AJ, Jones M and Evans C: Causes of discordance between thyroglobulin antibody assays. Ann Clin Biochem 49: 463-467, 2012.

35. Lee IS, Hsieh AT, Lee TW, Lee TI and Chien YM: The association of thyrotropin and autoimmune thyroid disease in developing papillary thyroid cancer. Int J Endocrinol 2017: 5940367, 2017.

36. Zhang L, Li H, Ji QH, Zhu YX, Wang ZY, Wang Y, Huang CP, Shen Q, Li DS and Wu Y: The clinical features of papillary thyroid cancer in hashimoto's thyroiditis patients from an area with a high prevalence of hashimoto's disease. BMC Cancer 12: 610, 2012.

37. Baser H, Topaloglu O, Tam AA, Evranos B, Alkan A, Sungu N, Dumlu EG, Ersoy R and Cakir B: Higher TSH can be used as an additional risk factor in prediction of malignancy in euthyroid thyroid nodules evaluated by cytology based on bethesda system. Endocrine 53: 520-529, 2016.

38. Fiore E, Rago T, Latrofa F, Provenzale MA, Piaggi P, Delitala A, Scutari M, Basolo F, Di Coscio G, Grasso L, et al: Hashimoto's thyroiditis is associated with papillary thyroid carcinoma: Role of TSH and of treatment with L-thyroxine. Endocr Relat Cancer 18: 429-437, 2011.

39. Latrofa F, Ricci D, Grasso L, Vitti P, Masserini L, Basolo F, Ugolini C, Mascia G, Lucacchini A and Pinchera A: Characterization of thyroglobulin epitopes in patients with autoimmune and non-autoimmune thyroid diseases using recombinant human monoclonal thyroglobulin autoantibodies. J Clin Endocrinol Metab 93: 591-596, 2008.

40. Sinclair D: Clinical and laboratory aspects of thyroid autoantibodies. Ann Clin Biochem 43: 173-183, 2006.

41. Zhao L, Liu M, Gao Y, Huang Y, Lu G, Gao Y, Guo X and She B: Glycosylation of sera thyroglobulin antibody in patients with thyroid diseases. Eur J Endocrinol 168: 585-592, 2013.

(7) 9 This work is licensed under a Creative Commons Attribution-NonCommercial-NoDerivatives 4.0 International (CC BY-NC-ND 4.0) License. 